\title{
Association between Myeloperoxidase and High Sensitive Troponin I on Myocardial Contractility in Acute Myocardial Infarction Patients
}

\author{
Trisulo Wasyanto' ${ }^{1)}$, Budi Patria Meilus's), Ahmad Yasa') \\ 1)Department of Cardiology and Vascular Medicine, Faculty of Medicine, \\ Universitas Sebelas Maret/Dr. Moewardi Hospital, Surakarta \\ ${ }^{2)}$ Departmentof Cardiology and Vascular Medicine, Faculty of Medicine \\ Universitas Sebelas Maret
}

\section{ABSTRACT}

Background: Myeloperoxidase (MPO) levels have been shown to have prognostic values for death events in acute myocardial infarction (AMI) patients. Increased levels of high sensitive troponin I (hs Trop I) are associated with poorer prognosis in AMI patients. This study aimed to determine the association between levels of MPO and hs troponin I at admisson on myocardial contractility in AMI patients.

Subjects and Method: This was a prospective observational analytic study, conducted at Dr. Moewardi General Hospital, Surakarta, from November1, 2018 to January 31, 2019. The study subjects were patients who were diagnosed with AMI. A total of 23 patients were included in this study; 15 patients with ST elevation myocardial infarction (STEMI) and 8 with non ST elevation myocardial infarction (NSTEMI). The dependent variable was myocardial contractility. The independent variables were MPO and hs Trop I. Blood tests for MPO and hs Trop I was measured at admission and the left ventricular ejection fraction (LVEF) was measured when predischarge by the Simpson method to examine myocardial contractility. The data were analyzed by Pearson correlation run on SPSS 22.

Results: hs Trop I $(\mathrm{r}=-0.53 ; \mathrm{p}=0.009)$ and MPO ( $\mathrm{r}=-0.15 ; \mathrm{p}=0.487)$ decreased LVEF.

Conclusion: Hs Trop I at admission has a correlation with myocardial contractility, and no correlation of MPO at admission with myocardial contractility in AMI patients.

Keywords: Myeloperoxidase, High sensitive Troponin I, Acute myocardial infarction

\section{Correspondence:}

Trisulo Wasyanto. Department of Cardiology and Vascular Medicine, Faculty of Medicine, Universitas Sebelas Maret/ Dr. Moewardi Hospital. Jl. Kol. Sutarto 132, Surakarta 57126, Central Java, Indonesia. Email: trisulo.wasyanto@gmail.com.

Cite this as:

Wasyanto T, Meilus BP, Yasa A (2020). Association between Myeloperoxidase and High Sensitive Troponin I on Myocardial Contractility in Acute Myocardial Infarction Patients. Indones J Med. 05(04): 265-271. https://doi.org/10.26911/theijmed.2020.05.04.01.

(c) (i) (-) Indonesian Journal of Medicine is licensed under a Creative Commons (cc) $\mathrm{EY}$ NC SA Attribution-Non Commercial-Share Alike 4.0 International License.

\section{BACKGROUND}

Coronary heart disease (CHD) is one of the most common and leading causes of death worldwide. Acute myocardial infarction (AMI) is triggered by systemic inflammatory process in the atherosclerotic plaques and myocardium. The incidence of AMI with ST segment elevation (STEMI) is in the range of 43 to 144 in 100,000 cases per year in Europe
(Widimsky et al., 2010). In Indonesia, the incidence of CHD is increasing, according to data from basic health research (Riskesdas) in 2013, the prevalence of CHD in Indonesia based on diagnosis and symptoms ranges from $0.5 \%$ - 1.5\% (Balitbang Kemenkes RI, 2013). Acute myocardial infarction (AMI) is a form of severe cardiovascular disease which is the development of chronic atherosclerotic 
lesions and acute thrombosis, due to atheroma plaque rupture formed by oxidation of low density lipoprotein (LDL), endothelial dysfunction, resulting in myocardial ischemia lesions and acute thrombosis (Pashkow, 2011).

Myeloperoxidase (MPO) is the largest protein component in azurophilic granulocytes, namely polymorphonuclear (PMN) leukocytes. MPO is a member of a subfamily of peroxidases; it is mostly expressed in immune cells such as PMN cells, lymphocytes, monocytes, and other macrophages and cells. It is stored in the cytoplasmic membrane and binds to azurophilic granules. It plays a potential role worsen the atherosclerosis process. It is produced when leukocytes are activated, and it plays a role in the formation of foam cells, endothelial dysfunction and apoptosis, matrix metalloproteinase (MMP) activation, and the expression of tissue factors to produce vulnerable plaque. Mieloperoksidase is part of heme peroxidase, causing various reactive oxidants and radical species that can diffuse so that it is able to initiate fat peroxidase and trigger posttranslational modification of protein targets, including halogenation, nitration, and oxidative cross reactions (Podrez et al., 2000; Heinecke, 2003). High MPO plasma levels have been shown to have prognostic values for death events and major adverse cardiovascular events (MACE) in IMA patients (Kaya et al., 2012) with better prognostic values compared to NT-proBNP (Kacprzak and Zielinska, 2016).

Early diagnosis of IMA is necessary, therefore high-sensitive of Troponin I (hsTnI) examination is still the first choice of biomarkers for diagnosing AMI. Complications of myocardial necrosis cause heart failure, myocardial rupture, and arrhythmia (Chan and $\mathrm{Ng}, 2010$; Twerenbold et al., 2017). Decreased myocardial contractility is a complication of AMI that can result in a heart failure or cardiogenic shock, and this event will increase the risk of morbidity and mortality in post-IMA patients by $81 \%$ within 30 days of treatment (Khan et al., 2013; Mello et al., 2014).

\section{SUBJECTS AND METHOD}

\section{Study Design}

This study uses a prospective observational analytic study design. The study was conducted at the Emergency Room and Intensive Cardiovascular Care Unit (ICVCU) at Dr. Moewardi General Hospital Surakarta in STEMI and NSTEMI patients.

\section{Population and Sample}

A total of 23 patients with AMI were included in this study; 15 patients with ST elevation myocardial infarction (STEMI) and 8 with non ST elevation myocardial infarction (NSTEMI). This study was conducted from November1, 2018 to January 31, 2019at Dr. Moewardi General Hospital and selected by consecutive sampling.

\section{Study Variables}

The dependent variable was myocardial contractility by measuring the left ventricular ejection fraction (LVEF) using the Simpson method. The independent variables were myeloperoxidase(MPO) and hs troponin I (hs-TropI).

\section{Study Instruments}

Blood tests for MPO and hs Trop I was measured at the Emergency Room and the LVEF was measured when pre discharge using the Simpson method to examine myocardial contractility with the GE Vivid 6 echocardiography machine. MPO levels were measured using Human Myeloperoxidase Immunoassay Quantikine ELISA (R\&D System, USA), conducted at the Prodia Clinical Laboratory. The level of hs-Trop I was measured using Vidas high-sensitive Troponin I (Biomerieux SA Tech, Lyon, France), done at the Clinical Pathology Laboratory of Dr. Moewardi Hospital. 
Wasyanto et al./ Myeloperoxidase, High Sensitive Troponin I, and Myocardial Contractility

\section{Data Analysis}

Pearson correlation analysis is used to determine the association between the MPO variable with the LVEF variable and the association between the hs-TropI variable and the LVEF variable. Pearson correlation coefficients are expressed in notation r. Data analysis was performed with SPSS 22.

\section{Research Ethics}

The research ethics include inside informed consent, identity confidentiality, and ethical clearance carried out in the Dr. Moewardi hospital, Surakarta.

Table 1. Sample characteristics

\begin{tabular}{lcccc}
\hline Variables & Mean & SD & Minimum & Maximum \\
\hline Age & 58.96 & 9.89 & 45 & 85 \\
SBP & 129.78 & 24.51 & 82 & 185 \\
DBP & 80.39 & 16.26 & 50 & 120 \\
Heart Rate & 80.35 & 17.80 & 55 & 140 \\
Respiratory Rate & 21.30 & 3.27 & 18 & 32 \\
Hemoglobin & 13.23 & 1.75 & 10.10 & 17.50 \\
Hematocrit & 40.26 & 5.49 & 31 & 52 \\
Leukocyte & 15.95 & 22.01 & 5.90 & 109.00 \\
Platelets & 238.80 & 76.91 & 234.50 & 386.00 \\
Erythrocytes & 4.53 & 0.66 & 3.39 & 5.72 \\
eGFR & 64.74 & 28.83 & 29 & 156 \\
Total cholesterol & 182.57 & 94.75 & 137 & 553 \\
LDL & 127.00 & 70.07 & 54 & 815 \\
HDL & 42.61 & 15.08 & 20 & 240 \\
Triglycerides & 113.61 & 49.24 & 11 & 271.90 \\
STEMI: & & & & $7,495.00$ \\
MPO (ng/mL) & 181.49 & 74.67 & 44.70 & 56 \\
hs-TnI (ng/L) & $2,176.60$ & $2,345.55$ & 5.90 & 270.90 \\
LVEF (\%) & 44.53 & 6.15 & 33 & $6,000.00$ \\
NSTEMI: & & & & 61 \\
MPO(ng/mL) & 149.79 & 91.16 & 23.30 & \\
hs-TnI (ng/L) & 946.56 & $1,473.65$ & 9.20 & 34 \\
LVEF (\%) & 43.50 & 9.37 & &
\end{tabular}

$\mathrm{SBP}=$ Systolic blood pressure $\mathrm{LDL}=$ Low density lipoprotein.

$\mathrm{DBP}=$ Diastolic blood pressure

$\mathrm{HDL}=$ High density lipoprotein

Description of study characteristic variables are presented in Table 2. Table 2 showed that there was no difference between male (65\%) and female $(66.7 \%)$ to experience STMI $(\mathrm{OR}=$ $0.93 ; 95 \% \mathrm{CI}=0.07$ to $12.14 ; \mathrm{p}=0.955)$.

Hypertension increased the risk of STMI and it was statistically significant $(\mathrm{OR}=$ $6 ; 95 \% \mathrm{CI}=0.87$ to $41.22 ; \mathrm{p}=0.057)$.

\section{RESULTS}

The basic characteristics of the patients are presented in Table 1 . The patients were 23 people with divided into two groups, namely STEMI for 15 and NSTEMI 8 patients. The average age of patients was 58.96 years (Mean $=58.96 ; \mathrm{SD}=9.89$ ). They had ages ranging from 45 to 85 years. The average of systolic blood pressure was $129.78 \mathrm{mmHg}$ $(\mathrm{Mean}=129.78 ; \mathrm{SD}=24.51)$. 
Table 2. Bivariate analysis on the factors associated with acute myocardial infarction

\begin{tabular}{|c|c|c|c|c|c|c|c|c|}
\hline \multirow{3}{*}{$\begin{array}{c}\text { Independent } \\
\text { Variables }\end{array}$} & \multicolumn{4}{|c|}{ Acute myocardial infarction } & \multirow{3}{*}{ OR } & \multicolumn{2}{|c|}{$95 \%$ CI } & \multirow{3}{*}{$\mathbf{p}$} \\
\hline & \multicolumn{2}{|c|}{ STEMI } & \multicolumn{2}{|c|}{ NSTEMI } & & Lower & Upper & \\
\hline & $\mathbf{n}$ & \% & $\mathbf{n}$ & $\%$ & & limit & limit & \\
\hline \multicolumn{9}{|l|}{ Gender } \\
\hline Male & 13 & 65 & 7 & 35 & 0.93 & 0.07 & 12.14 & 0.955 \\
\hline Female & 2 & 66.67 & 1 & $33 \cdot 33$ & & & & \\
\hline \multicolumn{9}{|l|}{ Killip } \\
\hline Killip 1 & 10 & 76.92 & 3 & 23.08 & $3 \cdot 33$ & 0.56 & 19.95 & 0.179 \\
\hline Killip 2-4 . & 5 & 50 & 5 & 50 & & & & \\
\hline \multicolumn{9}{|l|}{ Hypertension } \\
\hline Yes & 10 & 83.33 & 2 & 16.67 & 6 & 0.87 & 41.22 & 0.057 \\
\hline No & 5 & $45 \cdot 45$ & 6 & 54.55 & & & & \\
\hline \multicolumn{9}{|l|}{ Smoking } \\
\hline Yes & 9 & 64.29 & 5 & 35.71 & 0.90 & 0.15 & 5.26 & 0.907 \\
\hline No & 6 & 66.67 & 3 & $33 \cdot 33$ & & & & \\
\hline \multicolumn{9}{|l|}{ Dyslipidemia } \\
\hline Yes & 1 & 50 & 1 & 50 & 0.50 & 0.03 & 9.24 & 0.636 \\
\hline No & 14 & 66.67 & 7 & 33.3 & & & & \\
\hline \multicolumn{9}{|l|}{ DM } \\
\hline Yes & 1 & $33 \cdot 33$ & 2 & 66.67 & 0.21 & 0.02 & 2.84 & 0.214 \\
\hline No & 14 & 70 & 6 & 30 & & & & \\
\hline
\end{tabular}

STEMI = ST elevation myocardial infarction

NSTEMI = Non ST elevation myocardial infarction

The results of the correlation analysis between MPO, Hs-TnI, and LVEF were presented in Table 3. Table 3 showed that statistically significant $(\mathrm{r}=-0.53 ; \mathrm{p}=0.009)$. MPO decreased LVEF, but it was statistically non-significant $(\mathrm{r}=0.15 ; \mathrm{p}=487)$.

Hs-TnI decreased LVEF and it was

Table 3. Pearson correlation between MPO and Hs-TnI with left ventricular ejection fraction

\begin{tabular}{ccc}
\hline Independent Variables & $\mathbf{r}$ & $\mathbf{p}$ \\
\hline MPO & -0.15 & 0.487 \\
Hs-TnI & -0.53 & 0.009 \\
\hline
\end{tabular}

\section{DISCUSSION}

The subjects of this study were STEMI and NSTEMI patients, then measured blood myeloperoxidase (MPO) and hs-TnI levels, and left ventricular ejection fraction (LVEF) measurements with the Simpson method to see the role of MPO and hs-TnI on myocardial contractility. This study aims to determine the association between levels of MPO and hs troponin I on myocardial contractility in AMI patients.

Myeloperoxidase plays a role in the promotion of vasoconstriction, leukocyte recruitment and also myocardial fibrosis.
Increased levels of MPO are associated with diastolic disorders, due to excess ventricular pressure which may be associated with leukocyte activation (Deusch et al., 2014). MPO may contribute to myocardial dysfunction, a side effect of remodeling after acute myocardial infarction through several potential mechanisms. MPO secretes several cytotoxic species, including aldehydes that can modify residues that serve as key ionic channels or transporters to impair contractile function after an ischemic episode. Ischemic phenomena and myocardial reperfusion 
stimulate polymorphonuclear (PMN) cell recruitment and are associated with microvascular dysfunction, contributing to decreased vascular bioavailability of nitric oxide (NO). The predominant mechanism is through rapid reaction with superoxide, which is a derivative of NADPH oxidase and PMNs, which accumulate and activate PMNs neutrophils in inflamed tissues (Baldus et al., 2004).

Myeloperoxidase can affect ventricular remodeling after infarction by activating proteases. Inactivation of PAI-1 with oxidation catalyzed with MPO, which increases plasmin activity will accelerate matrix degradation, which will thin the ventricular wall and dilate the heart chambers, while inhibition of MPO will result in decreased leukocyte infiltration, significant reduction in LV dilatation and good LV function (Askari et al., 2003).

Cardiac troponin I (cTnI) and T (cTnT) are components of the myocardial cell contractile apparatus and are expressed almost exclusively in the heart. An increase in troponin levels describes an injury to myocardial cells (Thygesen et al., 2018). Myocardial infarction can affect left ventricular function, wherein the extent or size of the infarct is directly related to left ventricular remodeling and is a stronger predictor of clinical outcome in patients with acute myocardial infarction than measurement of left ventricular systolic function (Wu et al., 2008).

Pearson correlation analysis showed that the MPO and LVEF variables did not have a significant correlation. The results of Pearson correlation analysis between the MPO variable and the LVEF indicate very weak negative correlation $(\mathrm{r}=-0.15 ; \mathrm{p}=$ 0.487). Statistical analyssis of data indicate no correlation between MPO at admission and myocardial contractility in patients with AMI.
Our results are in line with the study by Stankovic et al. (2012), who carried out serial examinations of MPO levels in AMI patients whose samples were taken at admission, 4, 8, 12, 24, and 48 hours of admission. All MPO levels taken at the time of the examination had a predictive value for mortality, except for MPO levels at admission. MPO levels associated with the incidence of heart failure were at 24 hours of admission. In addition, in a study by Kacprzak in 2016, MPO levels at admission were not associated with major cardiovascular events (PCI or unscheduled heart bypass surgery, stroke, reinfarction or death) in STEMI patients who underwent percutaneous coronary intervention (PCI). However, MPO levels at the time of treatment on the third and fourth days were predictors for major cardiovascular events (Stankovic et al., 2012).

The other results of this study indicate a negative correlation between hs-TropI and LVEF ( $\mathrm{r}=-0.53 ; \mathrm{p}=0.009$ ). This means, there is a correlation between hsTropI and myocardial contractility in patients with AMI. A high hsTropI level on admission correlates with low myocardial contractility in AMI patientsconclusively.

Findings in our study are in line with research by Khan et al. (2017), where in NSTEMI patients, troponin levels were negatively correlated with LVEF, where high troponin levels were associated with low LVEF, while low troponin levels had better LVEF. In addition, high troponin levels are also associated with poor outcomes. In addition, a study by Chia et al. (2008), also proved similar results, where 378 STEMI patients who underwent primary Percutaneous Coronary Intervention (primary PCI) showed that the troponin I value 72 hours was associated with infarct size at 5 and 30 days of treatment. Troponin I levels $>55$ $\mathrm{ng} / \mathrm{ml}$ were $90 \%$ sensitive for large infarct 
sizes ( $\geq 10 \%$ ) and low LVEF ( $\leq 40 \%$ ) with specificities of $70 \%$ and $52 \%$, respectively.

Based on the results of this study, it can be concluded that there is a correlation between hs-TropI and myocardial contractility and no correlation between MPO at admission and myocardial contractility in acute myocardial infarction patients.

\section{AUTHOR CONTRIBUTION}

Budi Patria Meilus and Ahmad Yasa collected the data, measured myeloperoxidase level, high sensitive troponin I. Trisulo Wasyanto examined clinical changes, left ventricular ejection fraction (LVEF) to examine myocardial contractility with echocardiography, did data analysis, and wrote the manuscript.

\section{CONFLICT OF INTEREST}

The authors declare there is no conflict of interest.

\section{FUNDING AND SPONSORSHIP}

No external funding and sponsorship.

\section{ACKNOWLEDGEIMENT}

We would like to thank to Dr. Moewardi Hospital that give permission to collect the data.

\section{REFERENCE}

Askari AT, Brennan ML, Zhou X, Drinko J, Morehead A, Thomas J, Topol E, Hazen S, Penn M (2003). Myeloperoxidase and plasminogen activator inhibitor 1 play a central role in ventricular remodeling after myocardial infarction. $\mathrm{J}$ Exp Med. 197(5): 615-24. https://doi.org/10.1084/jem.20021426.

Baldus S, Heitzer T, Eiserich JP, Lau D, Mollnau H, Ortak M, Petri S, et al. (2004). Myeloperoxidase enhances nitric oxide catabolism during myocardial ischemia and reperfusion. Free Radical Biology and Medicine, 37(6):
902-11. https://doi.org/10.1016/j.freeradbiomed.2004.06.003.

Balitbang Kemenkes RI (2013). Riset Kesehatan Dasar (RISKESDAS). Jakarta.

Chan D, Ng LL (2010). Biomarkers in Acute Myocardial Infarction. BMC Medicine. 8: 34-45.https://doi.org/10.1186/17417015-8-34

Chia S, Senatore F, Raffel OC, Lee H, Wackers FJT, Jang IK (2008). Utility of cardiac biomarkers in predicting infarct size, left ventricular function, and clinical outcome after primary percutaneous coronary intervention for STsegment elevation myocardial infarction. JACC Cardiovasc Interv. 1(4): 41523. https://doi.org/10.1016/j.jcin.2008.04.010.

de Mello BHG, Oliveira GBF, Ramos RF, Lopes BBC, Barros CBS, Carvalho EO, Teixeira FBP, et al. (2014). Validation of the Killip-Kimball classification and late mortality after acute myocardial infarction. Arq Bras Cardiol. 103(2): 107-17. https://dx.doi.org/10.5935\%2Fabc.20140091.

Deuschl F, Klinke A, Friedrichs K, Knappe D, Weinberger F, Müllerleile K, Westermann D, et al. (2014). Myeloperoxidase is critically linked to the development of diastolic heart failure following pressure overload. The Journal of Heart and Lung Transplantation, 33(4): S164.https://doi.org/10.1016/j.healun. 2014.01.440.

Heinecke JW (2003). Oxidative stress: new approaches to diagnosis and prognosis in atherosclerosis. Am $\mathrm{J}$ Cardiol. 91(3A):12A-16A. https://doi.org/10.1016/s0002-9149 (02)03145-4.

Kacprzak M, Zielinska M (2016). Prognostic value of myeloperoxidase concentration in patients with ST-segment elevation myocardial infarction treated with primary percutaneous coronary inter- 
Wasyanto et al./ Myeloperoxidase, High Sensitive Troponin I, and Myocardial Contractility

vention. Int $\mathrm{J}$ Cardiol. 223:452-7. https://doi.org/10.1016/j.ijcard.2016.07.258.

Kaya MG, Yalcin R, Okyay K, Poyraz F, Bayraktar N, Pasaoglu H, Boyaci B, Cengel A (2012). Potential role of plasma myeloperoxidase level in predicting long-term outcome of acute myocardial infarction. Texas Heart Institute Journal, 39(4): 500-6.

Khan HA, Alhomida AS, Sobki SH, Habib SS, Al Aseri Z, Khan AA, Al Moghairi A (2013). Serum markers of tissue damage and oxidative stress in patients with acute myocardial infarction. Biomedical Research. 24(1): 15-20. http://fac.ksu.edu.sa/sites/default/files-

/bio_medical_research_serum_marker_in_mi_2013.pdf.

Khan MH, Islam MN, Aditya GP, Islam MZ, Bhuiyan AS, Saha B, Bhowmick K, et al. (2017). Correlation of Troponin-I level with left ventricular ejection fraction and in-hospital outcomes after first attack of non-ST segment elevation myocardial infarction. Mymensingh Med J. 26(4): 721-31.

Pashkow FJ (2011). Oxidative stress and inflammation in heart disease: Do antioxidants have a role in treatment and/or prevention?. Int J Inflam. 514623. https://dx.doi.org/10.4061\%2F2$011 \% 2 \mathrm{~F} 514623$.

Podrez EA, Abu-Soud HM, Hazen SL (2000). Myeloperoxidase-generated oxidants and atherosclerosis. Free Radic Biol Med. 28(12): 1717-1725. https://doi.org/10.1016/so891-5849 (oo)o0229-x.

Stankovic S, Asanin M, Trifunovic D, MajkicSingh N, Ignjatovic S, Mrdovic I, Matic D (2012). Time-dependent changes of myeloperoxidase in relation to inhospital mortality in patients with the first anterior ST-segment elevation myocardial infarction treated by primary percutaneous coronary intervention. Clin Biochem. 45(7-8): 547-51. https://doi.org/10.1016/j.clinbiochem.2012.02.015.

Thygesen K, Alpert J, Jaffe A, Chaitman B, Bax J, Morrow D, White H (2018). Fourth universal definition of myocardial infarction. Global Heart, 13(4): 305-38. https://doi.org/10.1161/CIR.o000000000000617.

Twerenbold R, Boeddinghaus J, Nestelberger T, Wildi K, Rubini GM, Badertscher P, Mueller C (2017). Clinical use of highsensitivity cardiac troponin in patients with suspected myocardial infarction.J Am Coll Cardiol. 70(8): 996-1012. https://doi.org/10.1016/j.jacc.2017.07.718.

Widimsky P, Wijns W, Fajadet J, De Belder M, Knot J, Aaberge L, Andrikopoulos $\mathrm{G}$, et al. (2009). Reperfusion therapy for ST elevation acute myocardial infarction in Europe: description of the current situation in 30 countries. Eur Heart J. 31(8): 943-57. https://doi.org/10.1093/eurheartj/ehp492.

Wu E, Ortiz JT, Tejedor P, Lee DC, Bucciarelli-Ducci C, Kansal P, Carr JC, Holly TA, Lloyd-Jones D, Klocke FJ, Bonow RO (2008). Infarct size by contrast enhanced cardiac magnetic resonance is a stronger predictor of outcomes than left ventricular ejection fraction or end-systolic volume index: prospective cohort study. Heart, 94(6): 730-6. https://doi.org/10.1136/hrt.2007.122622. 